\title{
ARTICLE \\ Efficacy of Acid-treated Sawdust in Decolourization of Tanning Wastewater
}

\author{
M. Alhassan ${ }^{1^{*}}$ M. Suleiman ${ }^{1}$ A. A. Isah ${ }^{2}$ A. G. Abdulrashid ${ }^{1} \quad$ Y. Nasiru $^{1} \quad$ A. Bello ${ }^{1}$ \\ 1. Department of Chemistry, Sokoto State University, Sokoto, Nigeria \\ 2. Department of Chemistry, Usmanu Danfodiyo University, Sokoto, Nigeria
}

\section{ARTICLE INFO}

Article history

Received: 7 September 2021

Accepted: 23 September 2021

Published Online: 8 October 2021

\section{Keywords:}

Wastewater

Acid-modification

Sawdust

Physicochemical properties

\begin{abstract}
Colour removal from dye-bearing effluent is a serious challenge due to the difficulty in treating such wastewater by conventional treatment methods. The present investigation explores the decolourization of contaminated wastewater using acid-activated sawdust as an adsorbent. The physicochemical properties of wastewater samples labelled A, B, and C viz average temperature; $\mathrm{pH}$; electrical conductivity; and total dissolved solids were determined using standard methods to be $302.63 ; 6.1 ; 284.47 \mu \mathrm{S} / \mathrm{cm}$; $35116.66 \mathrm{mg} / \mathrm{L}$ respectively. Colour removal efficiency of the adsorbent was studied under variable conditions (contact time, rate of agitation, loading). Experimental results demonstrated that the sawdust adsorbent has a significant capacity for colour removal from tannery effluent. There was significant variation in the absorbance of the treated samples. Adsorbent dose, stirring rate, and contact time were found to be directly proportional to colour removal while $\mathrm{pH}$ variation of the samples show that the effluents became less alkaline (slightly acidic) after decolourization.
\end{abstract}

The uncontrolled release of tannery effluents (containing high COD, BOD levels, trivalent chromium, sulfides, sodium chloride, calcium, magnesium, organics, and other toxic ingredients) to the natural water bodies affect the plant and animals, the ecosystem and increases the health risk of human beings ${ }^{[3,4]}$.

Development of profitable and economically feasible way of curtailing the effects of tannery effluents cannot be overemphasized especially using local waste materials as precursors. Literature by ${ }^{[5-7]}$, reported an estimated production capacity of 1.8 billion metric tons of leather yearly, with a larger part of the product processed in Africa and Asia, factored by the high labour intensity involved in the manufacture and treatment of leather.

*Corresponding Author:

M. Alhassan,

Department of Chemistry, Sokoto State University, Sokoto, Nigeria; Email:mansuralhassan@gmail.com 
According to reports of ${ }^{[8,9]}$, colour removal in wastewater is one of the most difficult challenges to be addressed by textile finishing, tanning, dye manufacturing, pulp, and paper industries, among others.

Over the last few years, adsorption has gained importance as a separation, purification, and or detoxification process on an industrial scale. It has been used to purify ${ }^{[2]}$, decolorize ${ }^{[6-}$ ${ }^{8]}$, detoxify ${ }^{[12]}$, deodorize ${ }^{[2]}$, separate ${ }^{[4]}$, concentrate ${ }^{[5]}$, and recover the harmful products from liquid solutions and gas mixtures ${ }^{[9]}$.

Aerobic digestion is based on consumption of organic matter and its degredation to produce single cell protein, $\mathrm{CO}_{2}$ and water. Anaerobic digestion (AD) incorporates a series of interdependent biochemical reactions through the metabolic pathways of anaerobic microorganisms in the absence of air (oxygen). It is used as a pre-treatment step to improve efficiency and valorize organic mill waste (OMW) to achieve up to $80-85 \%$ COD, $59-87 \%$ reduction in toxicity, $65-95 \%$ removal of total phenols etc. Accordingly, Sungur and Özkan ${ }^{[10]}$, considered adsorption processes one of the best choices compared to other methods due to its convenience, ease of operation, simplicity of design, high efficiency, and wider applicability in water pollution control.

\section{Experimental}

\subsection{Sample Collection and Treatment}

The sawdust was collected from a local sawmill in Sokoto State. It was carefully screened, washed several times with distilled water to remove dirt (sand dust), colour and other surface adhering particles, filtered, dried in a thermostatic oven at $105^{\circ} \mathrm{C}^{[26]}$.

The dried sample was ground to smaller particles size with a mechanical blender and used for the preparation of the adsorbent. The tannery wastewater that was used was collected from a local tannery located at Tudun Wada and Bauchi Road areas of Sokoto State. The method of collection was by direct dipping of a $2 \mathrm{~L}$ plastic bottle into different depths of the effluent. The bottle was removed, covered, and brought to the laboratory for analysis. Adopting the method reported by ${ }^{[27]}$ the temperature, $\mathrm{pH}$, total dissolved solids and conductivity were determined as soon as the samples were brought to the laboratory. The samples were used as obtained without any treatment.

\subsection{Preparation of Adsorbent}

The method reported elsewhere ${ }^{[2]}$ was adopted for preparing the adsorbent. Powdered sawdust (150 g) was accurately weighed using an analytical balance and transferred into an empty $1000 \mathrm{~cm}^{3}$ beaker where 500 $\mathrm{cm}^{3}$ of $5 \%$ sulfuric acid $\left(\mathrm{H}_{2} \mathrm{SO}_{4}\right)$ solution was added. The mixture was placed on a magnetic stirrer/heating mantle for continuous stirring and heating at $32{ }^{\circ} \mathrm{C}$ for 24 $\mathrm{h}$ until a thick slurry was obtained. The slurry (acidified sawdust) was washed (continuously) with distilled water until a weakly acidic $\mathrm{pH}$ of more than 5 . The acidtreated sawdust was dried in a thermostatic oven at 50 ${ }^{\circ} \mathrm{C}$ overnight and then stored in a glass container before further investigations.

\subsection{Decolourization}

Tannery wastewater was used to evaluate the effectiveness of the acid-modified sawdust for decolourization. The temperature, $\mathrm{pH}$, conductivity, total dissolved solids, and colour of the tannery effluents were determined before and after the adsorption process. The physical properties of the effluent viz temperature, $\mathrm{pH}$, and conductivity were analyzed using a mercury thermometer, digital $\mathrm{pH}$ meter (Model KL031), and a conductivity meter respectively. Total Dissolved Solid was tested as per APHA standards. The adsorption studies were carried out at variable contact time (seconds), adsorbent dosage (g), and agitation speeds (revolutions per minute, rpm). Decolourization of the wastewater was carried out using the batch method as described elsewhere ${ }^{[28]}$.

\subsection{Adsorption Experiments}

\section{Effect of Variable Adsorbent Dosage}

Wastewater sample $\left(100 \mathrm{~cm}^{3}\right.$ each) was accurately measured and transferred into 3 containers $\left(500 \mathrm{~cm}^{3}\right.$ beakers) labelled A, B, and C. Adsorbent dosage of $5 \mathrm{~g}$, $10 \mathrm{~g}$, and $15 \mathrm{~g}$ at a constant agitation speed of $120 \mathrm{rpm}$ and contact time of 300 seconds were added to $\mathrm{A}, \mathrm{B}$, and $\mathrm{C}$ respectively. The mixtures were filtered and the filtrate was analyzed for the extent of decolourization.

\section{Effect of Agitation Speed /Stirring Rate}

To a similar set of beakers labelled A, B, and C, having $100 \mathrm{~cm}^{3}$ each of wastewater maintained for 300 seconds, containing $10 \mathrm{~g}$ of adsorbent each, the stirring rate was varied to $100 \mathrm{rpm}, 120 \mathrm{rpm}$, and $140 \mathrm{rpm}$ in A, B and C respectively. The mixture was filtered and the filtrates were analyzed for the extent of decolourization.

\section{Effect of Contact Time}

Wastewater samples $\left(100 \mathrm{~cm}^{3}\right)$ placed in beakers labelled $\mathrm{A}, \mathrm{B}$, and $\mathrm{C}$ containing $10 \mathrm{~g}$ each of the adsorbent stirred at 120rpm were maintained for 10, 20, and 30 minutes respectively.

The absorbance of the tannery wastewater was obtained 
using a UV-VIS spectrophotometer (Spectrum lab 23A) at a pre-optimized $\lambda_{\max }$ (wavelength corresponding to maximum absorption) as described by ${ }^{[1]}$. After equilibration and filtering of the adsorbent, the adsorbate solutions were examined for the extent of decolourization through the differences in absorbance.

\section{Results}

\subsection{Result of Physicochemical Parameters}

The result of physicochemical parameters of the tannery wastewater before and (after) decolourization is presented in Table 1.

Table 1. Physiochemical Parameters of Tannery wastewater

\begin{tabular}{|c|c|c|c|c|}
\hline \multicolumn{5}{|c|}{ Samples } \\
\hline Parameter & $\mathbf{A}$ & B & C & $\begin{array}{c}\text { SPL } \\
\text { (WHO, } \\
\text { 2002) }\end{array}$ \\
\hline $\begin{array}{c}\text { Temperature } \\
\text { (K) }\end{array}$ & $302.5(296.7)$ & $\begin{array}{c}302.8 \\
(299.5)\end{array}$ & $302.6(296)$ & N/A \\
\hline pH & $5.2(5.78)$ & $5.3(5.96)$ & $7.8(8.77)$ & $6.5-9.5$ \\
\hline $\begin{array}{c}\text { Electrical } \\
\text { Conductivity } \\
(\mu \mathrm{S} / \mathrm{cm})\end{array}$ & $15.62(25.89)$ & $\begin{array}{c}15.98 \\
(32.76)\end{array}$ & $\begin{array}{c}821.83 \\
(850.01)\end{array}$ & 1200 \\
\hline $\begin{array}{c}\text { Total Dissolved } \\
\text { Solids (mg/L) }\end{array}$ & $53470(5005)$ & $\begin{array}{l}23230 \\
(5235)\end{array}$ & $\begin{array}{l}28650 \\
(5306)\end{array}$ & 2100 \\
\hline Colour & $\begin{array}{l}\text { Brown } \\
\text { (Cloudy) }\end{array}$ & $\begin{array}{l}\text { Brown } \\
\text { (Cloudy) }\end{array}$ & $\begin{array}{l}\text { Brown } \\
\text { (Cloudy) }\end{array}$ & $\begin{array}{c}\text { Light } \\
\text { Permeable }\end{array}$ \\
\hline
\end{tabular}

SPL: Standard Permissible Limit ${ }^{[1]}$; values before and (after) adsorption.

\subsection{Results of Predetermined $\lambda_{\max } /$ Absorbance}

Table 2 presents the absorbance of samples at a predetermined wavelength $(630 \mathrm{~nm})$.

Table 2. Sample Absorbance at Predetermined Wavelength

\begin{tabular}{ccc}
\hline Sample & $\lambda_{\max }(\mathbf{n m})$ & Absorbance \\
\hline A & $490(204)$ & $2.232(0.929)$ \\
B & $410(186)$ & $2.146(0.973)$ \\
C & $490(201)$ & $0.094(0.038)$ \\
\hline
\end{tabular}

Values before and (after) decolourization.

\subsection{Result Variable of Adsorbent Dosage}

Table 3 shows the absorbance (at $490 \mathrm{~nm}$ ) of the various wastewater samples after treatment. 
samples before and after decolourization. However, ${ }^{[30]}$ reported a $\mathrm{pH}$ value of 10.5 , which is greater than the values recorded for the studied samples. The average $\mathrm{pH}$ value of 6.8 close to 7.8 recorded for sample $\mathrm{C}$ was also reported by ${ }^{[31]}$. This shows that the degree of acidity or alkalinity of tannery wastewater can vary greatly depending on the concentration of chemicals. The slight decrease in acidity in the $\mathrm{pH}$ values shows that the effluents became less alkaline (slightly acidic) after use. This confirms that they can be used for shaving hairs from the skins of animals. The $\mathrm{pH}$ values recorded for the wastewater in this study are within the standard discharge limit of $6.5-9.5$ as shown in the standard permissible limit (SPL) by the World Health Organization (WHO).

The electrical conductivity (EC) recorded in $\mu \mathrm{S} / \mathrm{cm}$ for the samples are 15.62, 15.98, and 821.83 accordingly while $25.89,32.76$, and 850.01 for treated samples respectively. The values for electrical conductivity (EC) in samples A (25.89) and B (32.76) are lower compared to 850.01 recorded in sample C. However, the three samples recorded an EC value that is within the standard of 1200 $\mu \mathrm{S} / \mathrm{cm}$ stipulated for the discharge of wastewater into the environment. These values are low compared to $1348 \mu \mathrm{S} /$ $\mathrm{cm}$ recorded by ${ }^{[1]}$. The variation in the total electrical conductivity may be dependent on the different kinds of chemicals used in the different stages of the tannery processes. The amount of total dissolved solids (TDS) recorded for samples A, B and C are in the order 53470, 23230 , and $28650 \mathrm{mg} / \mathrm{L}$ respectively. Reports by ${ }^{[2]}$ and ${ }^{[31]}$ presented lower TDS values of $14020 \mathrm{mg} / \mathrm{L}$ and 1318 $\mathrm{mg} / \mathrm{L}$ respectively. Compared to the values of $2100 \mathrm{mg} /$ $\mathrm{L}$ reported as the standard discharge limit for wastewater, values in this finding are much higher, which means that the tannery wastewater samples were quite polluted; samples A B and C are brownish in colour but became cloudy after decolourization.

Table 2 presents the results of the predetermined wavelength $(630 \mathrm{~nm})$ of maximum absorption (Lambda $\max$ ) and their corresponding absorbance values. The extent of colour removal was assessed based on the difference in absorbance of the sampled wastewater. Distilled deionized water was used as blank while the different wastewater samples were analyzed at 630 $\mathrm{nm}$. The observed Lamda max $\left(\lambda_{\max }\right)$ for the respective samples may be due to the various absorbing molecules contained in the sample solution. Samples A and C recorded absorbance of $490 \mathrm{~nm}$ each, before adsorption and 204 and $201 \mathrm{~nm}$ respectively after adsorption. By this similarity in absorbance, samples A and C likely contain similar absorbing molecules (though at different concentrations) than sample B whose absorbance is 410 $\mathrm{nm}$. The best condition for the colour removal of the wastewater samples is thus established from the initial absorbance obtained for the untreated tannery wastewater. This means that reduction in the absorbance obtained for the untreated wastewater samples was regarded as an indication of colour removal capability of the prepared adsorbent.

Table 3 displays the result of variable absorbance recorded for samples, A, B, and C, at stirring speed of 120 rpm for 5 min while the adsorbent dosages varied at 5,10 , and $15 \mathrm{~g}$ respectively. The colour removal efficacy of the prepared adsorbent was determined at a different dosage. It was observed that upon subjecting the samples to stated conditions and $5 \mathrm{~g}$ of the adsorbent, the absorbance values obtained were $1.873,1.913$, and 0.04 . When the adsorbent load was increased to $10 \mathrm{~g}$, there was a decrease in the absorbance values for samples A and B to 1.635 and 1.649 while there was no absorbance detected for sample C. Further increase in the adsorbent loading resulted to a decrease in absorbance values while there was no absorbance for sample C. This shows that adsorbent dosage is a significant factor in the removal of colour from tannery wastewater.

A difference of 0.238 in absorbance is noticed when the dosage is increased from $5 \mathrm{~g}$ to $10 \mathrm{~g}$ and 0.419 from $10 \mathrm{~g}$ to $15 \mathrm{~g}$ for sample A respectively. For sample B, the difference in absorbance values is 0.264 and 0.542 respectively, when the load was increased from $5 \mathrm{~g}$ to 10 $\mathrm{g}$ and from 10 to $15 \mathrm{~g}$.

The efficiency of the colour removal increased from $16.08 \%$ to $45.52 \%$ for sample A; from $10.86 \%$ to 48.42 $\%$ while it increased from $57.45 \%$ to $100 \%$ for sample $\mathrm{C}$ with increasing adsorbent dosage from 5 to $15 \mathrm{~g}$ for all samples. According to Sharma and Uma ${ }^{[33]}$, adsorption increased from 86.75 to $99.83 \%$ with increasing adsorbent dose from 0.40 to $0.60 \mathrm{~g}$. Accordingly, ${ }^{[34]}$ also reported an increase in removal efficiency for MB dye with an increasing amount of adsorbent.

The effect of stirring speed on colour removal of the samples, A, B, and C was presented in Table 4. Different agitation rates of 100, 120 and $140 \mathrm{rpm}$ at an adsorbent load of $10 \mathrm{~g}$ for 300 seconds. 10 grams of adsorbent was used because it gave the best colour removal capability from the previous experiment. At the speed of $100 \mathrm{rpm}$, the absorbance values of 1.220 and 1.121 were recorded for samples A and B while sample C does not show any absorbance. When the stirring speed was increased to $120 \mathrm{rpm}$ there was a slight decrease in the absorbance of the samples. A further increase in the stirring speed also resulted in a decrease in the values of the absorbance. Significant variation in absorbance values is attributed to 
shooting up of the stirring rate from $100 \mathrm{rpm}$ to $120 \mathrm{rpm}$ and $120 \mathrm{rpm}$ to $140 \mathrm{rpm}$.

Although the effects are not well pronounced as revealed by the present investigation, probably due to saturation and exhaustion of the binding sites on the adsorbents ${ }^{[32-33]}$.

Furthermore, the effect of contact time on colour adsorption by the prepared adsorbent was investigated. Table 5 shows the absorbance of samples A, B, and $\mathrm{C}$, with an adsorbent load of $10 \mathrm{~g}$ at a stirring speed of $120 \mathrm{rpm}$ for a period of $10 \mathrm{~min}, 20 \mathrm{~min}$ and $30 \mathrm{~min}$ respectively. For sample A, the absorbance dropped from 1.162 to 1.137 and further 1.121 at a contact time of 10 min and stirring speed of $120 \mathrm{rpm}$.

Sample B recorded a drop in value of absorbance from 1.083 to 1.049 and finally to 1.037 from 30 to 20 to 10 minutes respectively. Reduction in values of the absorbance is an indication of colour removal by the prepared adsorbent. The efficiency of removal is assessed by the level of reduction in the absorbance. It is obvious from Table 5 that time is an important parameter for the adsorption of colour on activated sawdust. The activated sawdust is also very effective in the removal of colour from sample C.

\section{Conclusions}

Based on the research findings, it can be seen that adsorbent dosage, stirring speed as well as contact time are all important factors in colour removal from wastewater. The adsorbing molecules of the constituent of coloured solution may also affect the efficiency of colour removal.

Adsorption of colour was influenced by various parameters such as adsorbent dosage, agitation speed, and contact time. Adsorption increased with increasing the quantity of adsorbent over an extended time and it was also observed that the efficiency of colour removal was concentration-dependent. The present investigation proved that adsorbents made from sawdust can be employed for the decolourization of tannery wastewater and will add to the existing technology of waste minimization. However, in order to establish its effectiveness, the current findings should be verified on an industrial (large) scale.

\section{References}

[1] A.U. Itodo, M.E. Khan, D.P. Feka and B. Ogoh, Journal of Water Technology and Treatment Methods, 2017, 1(1), 1-8.

[2] P. Kushwaha and K. Upadhyay, International Journal of Engineering Sciences and Research Technolo- gy, 2015, 4(4), 213-222.

[3] V. Midha and A. Dey, International Journal Chemical Science, 2008, 6(2), 472-486.

[4] T. Mandal, D. Dasgupta, S. Mandal, and Datta, Journal of Hazardous Materials, 2010, 180, 204-211.

[5] K. Pushpendra and U. Kanjan, International Journal of Chemical Studies, 2015, 3(1), 1-316.

[6] N. MorinCrini, Winterton, P., Fourmentin, S., Wilson, L.D., Fenyvesi, E. and G. Crini, Prog Polym Sci, 2017, 78(1), 1-10.

[7] P. Sharma, H. Kaur, M. Sharma, and V. Sahore, Environ. Monit. Assess., 2015, 183, 151-195.

[8] T. Robinson, G. McMullan, R. Marchant, and P. Nigam, Technol., 2013, 77, 247-255.

[9] G.Z. Kyzas and M. Kostoglou, Materials, 2014, 7, 333-364.

[10] S. Sungur, and A. Özkan, Nat. Eng. Sci., 2017, 2 (2), 111-118.

[11] M. Rafatullah, O. Sulaiman, R. Hashim, and A. Ahmad, Journal of Hazardous Material, 2010, 177, 7080.

[12] O. A. A. Eletta, S. I., Mustapha, O. A. Ajayi, and A. T. Ahmed, Nigerian Journal of Technological Development, 2018, 15(1), 26-32.

[13] I. Au, M. E. Khan, D. P. Feka and B. Ogoh, J. Water Technol Treat Methods, 2018, 1 (1), 104-110.

[14] T. Robinson, B. Chandran and P. Nigam, Bioresour. Technol., 2018, 84, 299-301.

[15] A.Y. Ugya, I.M. Toma and A. Abba, Sciences World Journal, 2015b, 10, 1-5.

[16] X. J. Jenitta, V. Daphne, V. Gnanasalomi, and J. J. Gnanadoss, J. Hazard. Mater., 2013, 155(3), 459468.

[17] S.R. Khan, M.A. Khwaja, A.M. Khan, H. Ghani and S. Kazmi, Water Res. 1999, 40, 3671-3682.

[18] M. Farenzena, L. Ferreira, J.O. Trierweiler and P.M. Aquim, Braz. Archive Biol. Technol., 2005, 48, 281289.

[19] C. Mant, S. Costa, J. Williams and E. Tambourgi, Bioresource Technol, 2006, 97, 1767-1772.

[20] A.K. Shanker, C. Cervantes, H. Loza-Tavera and S. Avudainayagam, Environ Int, 2005, 31, 739-753.

[21] N.C. Mondal, V.K. Saxena, and V.S. Singh, Current Science, 2005, 12 (25), 1-5.

[22] A. Favazzi, Pak. J. Engine. Appl. Sci., 2002, 1, 6166.

[23] C. Alfredo, D.P. Leondina and D. Enrico, Ind. Eng. Chem. Res., 2007, 46, 6825-6830.

[24] S.J.K. Naik, A.C. Pawer, K. Vani, K Madhuri and V.V, Devi, Indian pollution Research, 2007, 26 (2), 263265. 
[25] A.Y. Ugya and A. Aziz, Merit Research Journal of Medicine and Medical Sciences, 2016, 4(11), 476479.

[26] American Public Health Association, Standard Methods for the Examination of Water and Waste Water, 1999.

[27] M. Nur-E-Alam, A.S. Mia, F. Ahmad and M.M. Rahman, Applied Water Science, 2018, 8(129), 1-7.

[28] A. Aklilu, S. Mengistu and I. Fisseha, International Journal of Scientific and Research Publications, 2012, 2(12), 1-5.
[29] P. Babyshakila, Advanced Studies in Biology, 2009, 1(8), 391-398.

[30] M. Chowdhury, M.I Hossain, A. Kanti, T.K. Biswas, F.A. bin Azam and M.D. Hossain, Oriental Journal of Chemistry, 2019, 35(2), 597-604.

[31] G.L Tadesse and T.K. Guya, Advances in Life Science and Technology, 2017, 54, 58-67.

[32] Y.C. Sharma and S. Uma, J. Chem. Eng. Data, 2010, $55,435-439$.

[33] N.A. Fathy, O.I. El-Shafey and L.B. Khalil, ISRN Physical Chemistry, 2013, 1-16. 